\title{
Percutaneous Catheter Drainage of Pancreatic Pseudocysts: Five Years Experience
}

\author{
Osama M. Al Saeed ${ }^{a}$ Javier Casillas $^{b}$ Mehraj Sheikha \\ a Department of Radiology, Faculty of Medicine, Kuwait University, Kuwait; \\ bepartment of Radiology, University of Miami, Jackson Memorial Medical Center, Miami, Fla., USA
}

\section{Key Words}

Pancreatic pseudocyst - Interventional radiology •

Nonsurgical treatment · Percutaneous drainage

\begin{abstract}
Objective: Pancreatic pseudocysts are common complications of pancreatitis. Pseudocysts can be treated by various drainage procedures such as endoscopic cystenterostomy or transpapillary drainage, percutaneously with image guidance or operatively. We report our experience with image-guided percutaneous evacuation of pancreatic pseudocysts. Materials and Methods: This retrospective study was conducted on 37 consecutive patients who underwent 45 percutaneous catheter placements for the drainage of pseudocysts. The catheters were introduced under ultrasound or computerized tomography guidance. The patients were followed up with a fluoroscopic catheter check for evaluation of size of collection, communication with gastrointestinal tract and the pancreatic duct. The catheter was removed when the patient was asymptomatic and the output from the catheter was less than $10 \mathrm{~cm}^{3}$ in $24 \mathrm{~h}$. Results: Forty-five procedures of percutaneous drainage of pancreatic pseudocysts were performed in 37 consecutive patients. The size of the cysts ranged between 4 and $20 \mathrm{~cm}$. Drainage
\end{abstract}

\section{KARGER}

Fax + 41613061234

E-Mail karger@karger.ch

www. karger.com

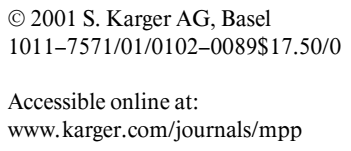

was performed on cysts larger than $5 \mathrm{~cm}$ in diameter. Forty-eight percent of the patients had communication with the pancreatic duct. Percutaneous drainage was successful in $95 \%$ of the cases in our study regardless of pseudocyst communication with the main pancreatic duct. The average duration of catheter drainage was 30 days in cases without communication versus 33 days in patients with communication with the pancreatic duct. Conclusion: Percutaneous drainage is a safe and effective alternative to surgery in patients with pancreatic pseudocysts. The duration of catheter drainage in cases with or without communication with the pancreatic duct was nearly the same.

Copyright $@ 2001$ S. Karger AG, Basel

\section{Introduction}

Pancreatic pseudocysts (PPs) account for 16-50\% of the complications of cases of acute pancreatitis, 20-40\% of the cases of chronic pancreatitis and 3.3-8\% following traumatic pancreatitis [1-3]. Untreated persistent pseudocysts have been associated with $40 \%$ of the complications, including abscess formation, fistulas, spontaneous rupture, massive hemorrhage and death [4]. Small (less than $5 \mathrm{~cm}$ ) asymptomatic cysts are generally treated con- 
servatively, whereas patients who are symptomatic (pain, fever or pressure effects) or have a pseudocyst of more than $5 \mathrm{~cm}$ in diameter are managed either surgically or through interventional radiology and/or endoscopic catheter placement [5]. Ultrasound-guided pseudocyst puncture was described in 1976 [6] and in the 1980s successful percutaneous drainage by interventional radiology was reported. With computerized tomography (CT) or ultrasound guided percutaneous catheter drainage (PCD), a 70-90\% success rate has been reported by various authors [4-15]. Some authors argue [7-13] that internal drainage avoids superinfection, fistula formation and allows debridement of sterile necrotic debris and generous biopsy of the PP wall for histological examination, while others [13-16] point out that PCD carries a low mortality rate and avoids major surgery.

This study was designed to analyze the outcome of image-guided PCD of PPs performed over a 5-year-period.

\section{Materials and Methods}

This retrospective study consists of 37 consecutive patients with PPs who underwent 45 percutaneous catheter placements for drainage from June 1992 to March 1997. The PPs were defined using criteria of the Atlanta Convention guidelines [17]. Patients with fluid collections and abscesses were excluded from the study. Hospital records of the patients with true PPs were reviewed for the following data: age, gender, clinical manifestations, previous treatment for pancreatitis or PP, cause, location, and size of pseudocysts. Followup information was obtained regarding length of hospital stay, results of treatment, and posttreatment morbidity and mortality. All patients had CT and ultrasound examination. An all-purpose pigtail drainage catheter (size range 6.7-10 F Medi-tech Flexima) was used for the cyst drainage. The catheters were introduced by Selding's technique, using either a direct transperitoneal approach or via a transgastric route under CT or ultrasound guidance. Depending upon the presence of a suitable window, the direct approach was preferred. The transgastric route was chosen when the direct approach was not possible. The initial aspirate was examined for color, consistency, culture, Gram stain and amylase levels.

Instructions for care of the catheter were provided to both the medical staff and the patients. Daily saline irrigation and output monitoring were recorded. The patients were followed up with a fluoroscopic catheter check for the evaluation of the size of the collection, communication with the gastrointestinal tract and the pancreatic duct and location of the catheter tip in relation to the collection. Follow-up CT scan and ultrasound were done when required. The criteria for catheter removal included an output of less than $10 \mathrm{~cm}^{3}$ per day and consideration as to whether the patient was afebrile and asymptomatic. The catheter was initially closed and a follow-up CT scan or ultrasound was performed after $48 \mathrm{~h}$ or earlier if the patient became symptomatic. In case of recollection, the catheter was reopened to external drainage with further follow-up.

90

Med Principles Pract 2001;10:89-92

\section{Results}

Forty-five procedures for PCD (25 under CT guidance and 20 under ultrasound guidance) were performed in 37 consecutive patients. There were 23 males and 14 females with an average age of 45.1 years (range 3-74 years). Thirty-four patients underwent the direct percutaneous approach, while 11 patients had transgastric puncture. The cause of pancreatitis and the patients' presentation are shown in tables 1 and 2, respectively. Eight pseudocysts were located in the head of the pancreas, 16 in the body and 21 in the tail. The size of the drained pseudocysts ranged between 4 and $20 \mathrm{~cm}$ in diameter. Multiple cysts were noted in 8 patients. In these patients, the larger cyst $(>5 \mathrm{~cm})$ was drained while the other cysts were clinically monitored. Out of these 8 cases, 5 cysts resolved completely while the other 3 significantly decreased in size. The catheter size used was $8 \mathrm{~F}$ in 24 patients, $10 \mathrm{~F}$ in 16 patients and $6.7 \mathrm{~F}$ in 5 patients.

PCD was successful in 35 of 37 (95\%) cases in our study irrespective of pseudocyst communication with the main pancreatic duct. Eighteen patients revealed communication with the pancreatic duct. The duration of catheter drainage ranged from 10 to 125 days with an average of 30 days in cases without communication, and 33 days in cases with communication with the main pancreatic duct. Eight pseudocysts required more than 60 days for drainage. Five of these were associated with necrotizing pancreatitis, 2 cases reaccumulated when the catheter was closed to external drainage and 1 case was lost for followup. Only one major complication was encountered during catheter placement and drainage (table 3).

This patient with PP secondary to biliary pancreatitis developed pancreatic phlegmon secondary to an infection of the pseudocyst after an initial drainage for nearly 4 weeks.

Infection as a minor complication was considered in situations where the initial tap was positive on culture and patients were afebrile with a normal white cell count and normal clinical course and follow-up. Patients with minor complications did not require any active management. Two patients required surgery, 1 with a major infection and the other with associated cholecystitis and pancreatitis.

Three recurrences which required repeated percutaneous catheter placement were observed following complete resolution of the pseudocyst and removal of the percutaneous catheter. The recurrences were noted in patients who had direct percutaneous drainage. None of the cases with transgastric drainage had recurrence. The re- 
Table 1. Various causes of pancreatitis

\begin{tabular}{lc}
\hline Cause of pancreatitis & Patients \\
\hline Alcoholism & 15 \\
Biliary & 11 \\
Postsurgical & 5 \\
Trauma & 3 \\
Idiopathic & 3 \\
\hline Total & 37 \\
\hline
\end{tabular}

Table 2. Presenting symptoms

\begin{tabular}{lc}
\hline Patient presentation & Patients \\
\hline Abdominal pain & 29 \\
Elevated amylase & 19 \\
Nausea and vomiting & 8 \\
Fever & 1 \\
\hline
\end{tabular}

Table 3. Complications

\begin{tabular}{lcc}
\hline & Major & Minor \\
\hline Infection $^{1}$ & 1 & 4 \\
Catheter migration $^{\text {Hematoma }}$ & - & 3 \\
Intraperitoneal leak & - & 2 \\
\hline \multicolumn{2}{l}{ This patient required surgery. } \\
\hline
\end{tabular}

peated drainage was successful. There was no incidence of procedure failure. There were no mortality related to the procedure; however, one mortality occurred in an HIVpositive patient secondary to septicemia.

\section{Discussion}

PP is one of the commonest complications of pancreatitis. Formation of pseudocysts generally requires 4 or more weeks from the onset of acute pancreatitis. With the advances in imaging techniques, more information is now available about the natural history of the pseudocyst formation. It has been reported to appear within 2 days and spontaneously resolve within 6 weeks in $20-54 \%$ of cases, especially when small in size $(<5 \mathrm{~cm})[1,4,18,19]$. Not all PPs require drainage. In general, pseudocysts are drained most often because of pain or if there is a clinical suspicion that they may be infected [13]. The indications for PP drainage include pain, suspected infection, persistance of large $(>5 \mathrm{~cm}) \mathrm{PP}$, increasing size of PP and biliary or gastrointestinal obstruction.

Even though PCD was described in 1883 [20], internal drainage by surgery has been the mainstay of treatment for PPs. Needle aspiration alone carries a recurrence rate of more than $70 \%$ and a cumulative risk of complications $[1,21]$ and patients may require multiple aspirations $[22$, 23]. This can be overcome by the use of an indwelling catheter $[21,24]$ introduced by direct cyst puncture or via a transgastric approach. The transgastric approach is relatively difficult because the operator has to negotiate the two walls of the stomach before entering the pseudocyst, which carries a higher risk of complication and procedure failure. With the improvement of technology and increasing experience, $\mathrm{PP}$ drainage is often carried out percutaneously under sonographic or CT guidance [13, 16, 25]. Sonographic guidance is preferred because it is quick, less expensive, does not involve radiation and can be used in real time. Its main disadvantage is bowel gas, which can mask the collection. CT guidance is used in such cases to identify a safe window for drainage. When a direct approach is not available, the cyst is accessed through the transgastric route. The reported success rate for PCD is $70-100 \%[13,16,26,27]$. The overall reported rate of failure is $16 \%$, ranging from 0 to $33 \%$ [11]. PCD has been claimed to be associated with lower morbidity (7.7 vs. $16.7 \%)$, mortality ( 0 vs. $7 \%$ ) and complication rates (5$7.8 \%$ vs. $16-38 \%$ ) than surgery $[7,13]$. The principal disadvantage of PCD is the resulting pancreatic fistula, which generally requires 6 weeks to close and in some cases, if the fistula persists, requires surgical drainage. Other disadvantages include clogging of the catheter with pancreatic debris, resulting in failure of drainage and infection secondary to the introduction of contaminating organisms. Heider et al. [29] in their study showed better results with surgical management compared to PCD. In a series by Adams and Anderson [7], 19\% of the cases that had PCD needed subsequent surgical treatment, while $50 \%$ had infection of the drainage track. We were successful in $95 \%$ from the first attempt. Three recurrences that occurred in patients who had direct puncture were successfully drained by repeating the drainage, resulting in a final percentage of $98 \%$. Only one major infection that required surgery was encountered in a patient with biliary pancreatitis. The other positive cultures from the initial aspiration (5 cases) were most likely due to contamination rather than real infection since these patients were afebrile with normal white cell count, and the cysts behaved like the noninfected ones over the period of follow-up. Another patient in our study who had surgical resection for the cyst also required surgery for biliary stones. Though Sanfey et al. [28] reported poor outcome of PCD of PPs arising after biliary pancreatitis, our success of PCD in such cases was also high, surgery being performed in only 2 out of 11 cases. 
It has been suggested that cyst communication with the pancreatic duct may be a factor in choosing between percutaneous and surgical drainage [27, 30]. D'Egidio and Schein [10] in their prospective study of 21 patients concluded that while PCD is the treatment of choice in pseudocysts with no ductal communication, it has no role in pseudocysts having ductal communication and associated strictures in the main pancreatic duct. In cases where the communicating duct is without obstruction, the drainage is quite prolonged. Similar views are expressed by Ahearne et al. [30].

In our study communication with the main pancreatic duct did not significantly affect the duration of catheter drainage. Forty-eight percent of our patients developed communication with the pseudocyst. The mean duration of drainage of those patients was 33 days compared to 30 days in patients with no communication. Our results compare favorably with Spivak et al. [31], who in their study of 27 patients had 12 ductal communications. However, there was no difference in outcome between patients with or without cyst communication. In our series, prolonged catheter drainage (more than 60 days) was observed in patients with necrotizing pancreatitis.

\section{Conclusion}

PCD is a safe, reliable and effective alternative to surgery in the management of PPs. In our study there was no significant difference in the duration of drainage in cases with or without communication with the pancreatic duct.

\section{References}

1 Grace P, Williams R: Modern management of pancreatic pseudocysts. Br J Surg 1993;80: 573-581.

2 O'Malley VP, Cannon JP, Postier RG: Pancreatic pseudocyst cause, therapy, results. Am J Surg 1985;150:680-682.

3 Siegelman SS: CT of fluid collection associated with pancreatitis. AJR Am J Roentgenol 1980; 134:1121-1132.

4 Bradley E, Clemens JL Jr, Gonzales AC: The natural history of pancreatic pseudocysts: A unified concept of management. Am J Surg 1979; 137:135-141.

5 Michael J Lee, Wittich GR, Mueller PR: Percutaneous intervention in acute pancreatitis. Radiographics 1998;18:711-724.

6 Hancke S, Petersen JE: Percutaneous puncture of pancreatic cysts guided by ultrasound. Surg Gynecol Obstet 1976;142:551-552.

7 Adams DB, Anderson M: percutaneous catheter drainage compared with internal drainage in the management of pancreatic pseudocysts. Ann Surg 1992;215:571-578.

8 Aurell Y, Forsberg L, Hederstrom E, Andersson R: Percutaneous puncture and drainage of pancreatic pseudocysts: A retrospective study. Acta Radiol 1990;31:177-180.

9 Civardi G, Fornari F, Cavanna L, Sbolli G, Di Stasi M, Buscarini L: Ultrasonically guided percutaneous drainage of abdominal fluid collections: A long-term study of its therapeutic efficacy. Gastrointest Radiol 1990;15:245250.

10 D'Egidio A, Schein M: Percutaneous drainage of pancreatic pseudocysts: A prospective study. World J Surg 1991;16:141-146.

11 Grosso M, Gandini G, Cassinis M: Percutaneous treatment [including pseudocyst gastrostomy] of 74 pancreatic pseudocysts. Radiology 1989; 173:493-497.
12 Stanley J, Gobien R, Schabel SI, Andriole JE, Anderson MC, Smith RW: Percutaneous drainage of pancreatic and peripancreatic fluid collections. Cardiovasc Intervent Radiol 1988; 11:21-25.

13 von Sonnenberg E, Wittich G, Casola G: Percutaneous drainage of infected and noninfected pancreatic pseudocysts: Experience in 101 cases. Radiology 1989;170:757-761.

14 Frey CE: Pancreatic pseudocyst operative strategy. Ann Surg 1978;188:652-662.

15 Yeo CJ, Sarr MG: Cystic and pseudocystic diseases of the pancreas. Curr Probl Surg 1994;31: 165-243.

16 Criado E, DeStefano AA, Weiner TM, Jaques PE: Long-term results of percutaneous catheter drainage of pancreatic pseudocysts. Surg Gynecol Obstet 1992;175:293-297.

17 Bradley E III: A clinically based classification system for acute pancreatitis: Summary of the International Symposium on Acute Pancreatitis. Arch Surg 1993;128:586-590.

18 Sankuran S, Walt AJ: The natural and unnatural history of pancreatic pseudocysts. Br J Surg 1975;62:37-44.

19 Yeo CJ, Bastidas JA, Lynch-Nyhan A, Fishman EK, Zinner MJ, Cameron JL: The natural history of pancreatic pseudocysts documented by computed tomography. Surg Gynecol Obstet 1990;170:411-417.

20 Gussenbauer C: Zur operativen Behandlung der Pankreascysten. Arch Klin Chir 1883;29: 355-364.

21 Freeny PC: Percutaneous management of pancreatic fluid collections. Baillère's Clin Gastroenterol 1992;6:259-272.

22 Torres WE, Evert BM, Baumgartner BR, Bernardiono ME: Percutaneous aspiration and drainage of pancreatic pseudocysts. AJR Am J Roentgenol 1986;147:1007-1009.
23 van Sonnenberg E, Wittich GR, Cassola G, Stauffer AE, Polansky AD, Coons HG, Cabrera OA, Gerver PS: Complicated pancreatic inflammatory disease: Diagnostic and therapeutic role of interventional radiology. Radiology 1985; $155: 335$.

24 Gumaste UV, Dave PB: Pancreatic pseudocyst drainage: The needle or the scalpel? J Clin Gastroenterol 1991;13:500-505.

25 Karlson KB, Martin EC, Fankuchen EI, Mattern RF, Schultz RW, Casarella WJ: Percutaneous drainage of pancreatic pseudocyst and abscesses. Radiology 1982;142:619-624.

26 Barthel M, Bugallom Moreira LS, Bastid C, Sastre B, Sahel J: Management of cysts and pseudocysts complicating chronic pancreatitis: A retrospective study of 143 patients. Gastroenterol Clin 1993;17:270-276.

27 D'Egidio A, Schein M: Pancreatic pseudocyst: Proposed classification and its management implications. Br J Surg 1991;78:981-984.

28 Sanfey H, Aguilar M, Jones RS: Pseudocysts of the pancreas: A review of 97 cases. Am Surg 1994;60:661-668.

29 Heider R, Meyer AA, Galanko JA, Behms KE: Percutaneous drainage of pancreatic pseudocysts is associated with a higher failure rate than surgical treatment in unselected patients. Ann Surg 1999;229;6:781-789.

30 Ahearne PM, Baillie JG, Cotton PB, Baker ME, Meyers WC, Pappas T: An endoscopic retrograde cholangiopancreatography [ERCP]based algorithm for the management of pancreatic pseudocysts. Am J Surg 1992;163:111116.

31 Spivak H, Galloway J, Amerson JR, Fink AS, Branum GD, Red Vanky RD, Richardson WS, Mauren SJ, Waring JP, Hunter JG: Management of pancreatic pseudocysts. J Am Coll Surg 1998;186:507-511. 